\title{
Planetary Boundaries Analysis of Low-Carbon Ammonia Production
}

\section{Routes}

\section{Journal Article}

\section{Author(s):}

D'Angelo, Sebastiano Carlo (D); Cobo Gutiérrez, Selene (D); Tulus Merlich, Victor (D); Nabera, Abhinandan; Martín Fernández, Antonio José (D); Pérez-Ramírez, Javier; Guillén Gosálbez, Gonzalo (i)

\section{Publication date:}

2021-07-26

Permanent link:

https://doi.org/10.3929/ethz-b-000500189

\section{Rights / license:}

Creative Commons Attribution 4.0 International

\section{Originally published in:}

ACS Sustainable Chemistry \& Engineering 9(29), https://doi.org/10.1021/acssuschemeng.1c01915 


\title{
Planetary Boundaries Analysis of Low-Carbon Ammonia Production Routes
}

\author{
Sebastiano Carlo D’Angelo, Selene Cobo, Victor Tulus, Abhinandan Nabera, Antonio José Martín, \\ Javier Pérez-Ramírez,* and Gonzalo Guillén-Gosálbez*
}

Cite This: ACS Sustainable Chem. Eng. 2021, 9, 9740-9749

Read Online

\section{ACCESS | Llll Metrics \& More | 国 Article Recommendations | Sl Supporting Information}

ABSTRACT: At present, the synthesis of ammonia through the Haber-Bosch (HB) process accounts for $1.2 \%$ of the global carbon emissions, representing roughly one-fourth of the global fossil consumption from the chemical industry, which creates a pressing need for alternative low-carbon synthesis routes. Analyzing seven essential planetary boundaries (PBs) for the safe operation of our planet, we find that the standard $\mathrm{HB}$ process is unsustainable as it vastly transgresses the climate change $\mathrm{PB}$. In order to identify more responsible strategies from this integrated perspective, we assess the absolute sustainability level of 34 alternative routes where hydrogen $\left(\mathrm{H}_{2}\right)$ is supplied by steam methane reforming with carbon capture and storage, biomass gasification, or water electrolysis powered by various energy

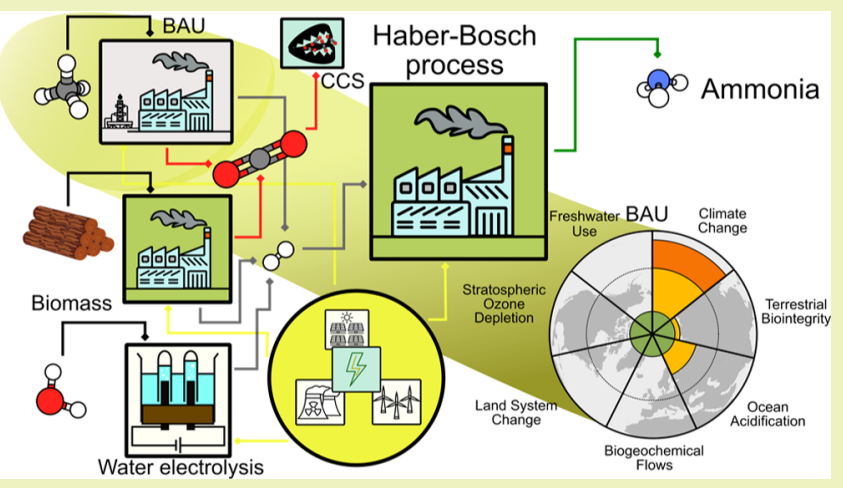
sources. We found that some of these scenarios could substantially reduce the global impact of fossil HB, yet alleviating the impact on climate change could critically exacerbate the impacts on other Earth-system processes. Furthermore, we identify that reducing the cost of electrolytic $\mathrm{H}_{2}$ is the main avenue toward the economic appeal of the most sustainable routes. Our work highlights the need to embrace global impacts beyond climate change in the assessment of decarbonization routes of fossil chemicals. This approach enabled us to identify more suitable alternatives and associated challenges toward environmental and economically attractive ammonia synthesis.

KEYWORDS: ammonia synthesis, Haber-Bosch process, LCA, planetary boundaries, renewables, techno-economic analysis

\section{INTRODUCTION}

Today, ammonia $\left(\mathrm{NH}_{3}\right)$ is the world's second largest (on a mass basis) chemical, with more than $170 \mathrm{Mt}$ produced annually. ${ }^{1}$ The main application of this chemical is fertilizers (>88\%), followed by explosives, plastics, and synthetic fibers. ${ }^{1,2}$ At present, more than $90 \%$ of $\mathrm{NH}_{3}$ global production uses the Haber-Bosch (HB) process. ${ }^{3}$ More than 50 years ago, $\mathrm{NH}_{3}$ plants were highly energy-intensive, using approximately $60 \mathrm{GJ}$ $\mathrm{t}^{-1} \mathrm{NH}_{3}$. However, energy efficiency improvements reduced energy requirements by half. ${ }^{4}$ Despite these significant savings, the HB process still represents $24 \%$ of the fossil fuel consumption in the chemical industry due to the hydrogen $\left(\mathrm{H}_{2}\right)$ required for $\mathrm{NH}_{3}$ synthesis. ${ }^{5} \mathrm{H}_{2}$ is mostly generated via steam methane reforming (SMR), which leads to a carbon footprint of $1.5-1.6 \mathrm{~kg} \mathrm{CO}$-eq $\mathrm{kg}^{-1} \mathrm{NH}_{3}$, accounting for $>1.2 \%$ of the global carbon emissions. ${ }^{6}$ This amount is roughly equivalent to the total $\mathrm{CO}_{2}$ emissions from South Africa in 2017. ${ }^{7}$ There is, therefore, a strong motivation to improve the sustainability level of fossil $\mathrm{NH}_{3}$ production.

Ongoing research efforts focus on decarbonizing $\mathrm{NH}_{3}$ production following two main strategies: (i) decarbonizing the electricity mix powering the business-as-usual (BAU) process $^{8}$ and (ii) replacing the fossil SMR $\mathrm{H}_{2}$ (grey $\mathrm{H}_{2}$ ) with greener $\mathrm{H}_{2}$ sources. The latter technologies rely on electrolytic $\mathrm{H}_{2}$ powered by renewable energy (green $\mathrm{H}_{2}$ ) and $\mathrm{H}_{2}$ from biomass gasification (BG)..$^{9-11}$ The direct electroreduction of elemental nitrogen $\left(\mathrm{N}_{2}\right)$ using air as feedstock and water as the proton source is also gaining momentum, yet it is still at a fundamental stage; notably, the lack of reliable benchmark catalysts and the low efficiencies generally reported represent a barrier to overcome. ${ }^{12-14}$

Quantifying the life cycle impact of these emerging technologies to decarbonize fossil $\mathrm{NH}_{3}$ is critical to identify the most sustainable ones. ${ }^{15}$ Since its emergence, life cycle assessment (LCA) has enabled comprehensive environmental analyses of processes and products, covering activities from raw material extraction to waste management. ${ }^{16-19}$ Several studies

Received: March 19, 2021

Revised: June 9, 2021

Published: July 12, 2021 
applied LCA to evaluate $\mathrm{NH}_{3}$ production technologies, focusing mainly on those coupling carbon capture and storage (CCS) with the BAU process ${ }^{20-23}$ and using $\mathrm{H}_{2}$ from water electrolysis, ${ }^{8,20,24-29} \mathrm{BG},{ }^{23,30}$ and $\mathrm{CuCl}$ cycles $^{8,26}$ to lower the carbon footprint. ${ }^{6}$ In terms of $\mathrm{N}_{2}$ sources, most of these studies considered cryogenic air separation for $\mathrm{N}_{2}$ procurement, while some covered pressure swing adsorption (PSA) and membrane separations as well..$^{20,23,27,29} \mathrm{LCAs}$ of $\mathrm{NH}_{3}$ production often focused on analyzing the carbon footprint, while only a few studied other impact categories, for example, human toxicity and abiotic resource depletion ${ }^{8,22-26}$ as well as eutrophication

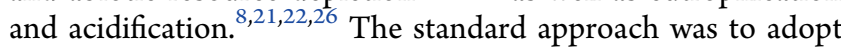
an attributional cradle-to-gate scope, although consequential LCA was also recently applied. ${ }^{23}$ In terms of uncertainties, many works omitted them while some applied Monte Carlo simulation $^{8,24,25}$ or sensitivity analyses to study the most critical uncertain parameters. $^{29-31}$

The main limitation of standard LCAs, widespread in the assessment of chemicals, is that they allow comparing and ranking alternatives but cannot help determine whether a technology is sustainable in absolute terms. Absolute environmental sustainability assessments (AESA) emerged recently in the literature ${ }^{32}$ that consider the Earth's biophysical limits to interpret the LCA results. This approach relates the impact of a system with its maximum allowable impact, which is established by assigning a share of the ecological capacity of the planet to it.

The concept of planetary boundaries (PBs), originally introduced by Rockström et al. ${ }^{33}$ and later refined by Steffen et al., ${ }^{34}$ provides a comprehensive framework to precisely quantify absolute sustainability. The PBs define a set of critical biophysical limits on key Earth-system processes whose transgression could shift the current state of the planet. ${ }^{33,34}$ These limits jointly identify a safe operating space (SOS) that should be shared among all anthropogenic activities. ${ }^{34,35}$ Recent PB-LCIA methods provided characterization factors to quantify the impact of feedstocks, emissions, and waste on the Earth-system processes linked to the PBs, enabling the AESA of industrial systems. With this spirit, we recently applied the $\mathrm{PBs}$ concept in the assessment of $\mathrm{CO}_{2}$-based methanol production, and $\mathrm{H}_{2}$ and bioethanol supply chains. ${ }^{36,37}$ Despite these and other related works, absolute sustainability studies of industrial systems are still in their infancy, particularly concerning chemicals and fuels.

For the first time, we here quantify the absolute sustainability level of low-carbon $\mathrm{HB}$ processes in terms of seven $\mathrm{PBs}$ focusing mainly on the electricity and $\mathrm{H}_{2}$ source, namely, considering SMR coupled with CCS, BG, and alkaline electrolysis (AE) and proton exchange membrane (PEM) water electrolysis.

\section{METHODS}

We assessed three main alternative routes (SMR, water electrolysis, BG) to produce low-carbon $\mathrm{NH}_{3}$ implementing several configurations, yielding a total of 35 representative scenarios (13 discussed next and the rest available in the Supporting Information). The selection reported here covers multiple scenarios for each different technology for $\mathrm{H}_{2}$ production, including meaningful combinations of these technologies with different power supplies (see Figure 1 for a general overview). Our analysis combines process simulation, LCA principles, and a recently developed impact assessment model based on the PB concept, as discussed in detail next.

2.1. Process Modeling and Scenarios Definition. We developed a process flowsheet of the HB process in Aspen HYSYS

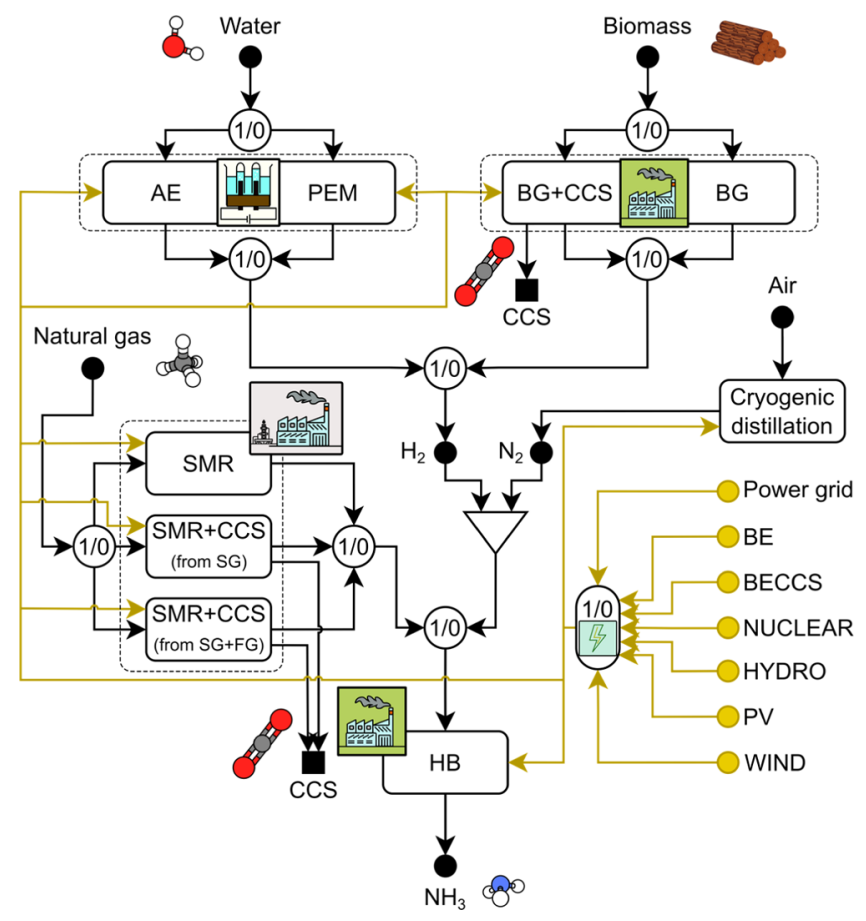

Figure 1. General graphic representation of the technologies included in this study. The acronyms are as follows: HB: Haber-Bosch; BAU: business-as-usual; SMR: steam methane reforming; CCS: carbon capture and storage; SG: syngas; FG: flue gas; AE: alkaline electrolysis; PEM: proton exchange membrane electrolysis; BG: biomass gasification; BE: bioenergy; BECCS; bioenergy with CCS; NUCLEAR: nuclear energy; HYDRO: hydropower; PV: photovoltaic energy; WIND: wind energy. The circle " $1 / 0$ " stands for a binary switch, which can be activated for any of the input streams and deactivated for every other one, with the only exception of the energy streams (see Section 2.1), where different power sources can be sent to different blocks.

v10 based on the process configuration, operating conditions, and kinetic parameters provided by Araújo and Skogestad. ${ }^{38}$ The plant was scaled to produce $560 \mathrm{kt} \mathrm{yr}^{-1}$ of $\mathrm{NH}_{3}$ using $\mathrm{H}_{2}$ and $\mathrm{N}_{2}$ as reactants, with a final purity above $99.5 \%$ on a mass basis. The reactants are fed in stoichiometric proportions, compressed to about $200 \mathrm{bar}$, and sent to the separation section, consisting of several flash units in series operating at different pressures and temperatures. This configuration improves the process controllability compared to directly sending the feed to the reactor inlet, especially when there are impurities that could damage the catalyst ${ }^{3}$ (e.g., $\mathrm{CO}_{2}$ and $\mathrm{H}_{2} \mathrm{O}$ ). The separation section separates liquid $\mathrm{NH}_{3}$ from the gaseous unreacted reactants, which are heated up to $\sim 230{ }^{\circ} \mathrm{C}$ and sent to an interquenched three-bed reactor loaded with the industrial iron-based HB catalyst. The reactor outlet is then cooled down to room temperature and then mixed with the fresh feed before entering the separation section. We provide additional details on the simulation in the Supporting Information. This simulation model was taken as a basis in all scenarios, differing in the $\mathrm{H}_{2}$ and electricity sources.

As $\mathrm{H}_{2}$ sources, we consider $\mathrm{SMR},{ }^{39}$ indirect $\mathrm{BG},{ }^{40,41}$ and electrolytic water splitting. ${ }^{42,43}$ The scenarios discussed herein are assumed to be deployed separately, that is, no integration in terms of material and energy inputs between different scenarios was considered. The electricity of the main process (compressors and pumps of the HB process) is supplied by the current mix, a future mix based on projections, or a dispatchable power source (i.e., nuclear or hydroelectric). Concerning SMR, currently, the conventional and cheapest route toward $\mathrm{H}_{2},{ }^{6}$ we consider SMR without $\mathrm{CO}_{2}$ capture (BAU), SMR with CCS storing the $\mathrm{CO}_{2}$ from the generated syngas in a geological reservoir $\left(\mathrm{SMR}+\mathrm{CCS}_{\mathrm{SG}}\right)$, and $\mathrm{SMR}$ where all $\mathrm{CO}_{2}-$ from the generated syngas and that produced in the combustion of 
natural gas to heat the reformer-undergoes CCS (SMR + $\left.\mathrm{CCS}_{\mathrm{SG}+\mathrm{FG}}\right)$. Storing the $\mathrm{CO}_{2}$ present in the syngas only requires additional compressors; however, a capture unit must be deployed to separate the $\mathrm{CO}_{2}$ in the flue gas of the external furnace. Additional details on these scenarios are provided in the Supporting Information.

$\mathrm{BG}$ is regarded as an environmentally promising alternative for electricity and $\mathrm{H}_{2}$ production. ${ }^{4,9,23,30}$ Coupling BG with CCS allows producing carbon-negative $\mathrm{H}_{2}$ (on a cradle-to-gate basis). ${ }^{44}$ Accordingly, here, we cover $\mathrm{BG}^{40}$ and $\mathrm{BG}$ with $\mathrm{CCS},{ }^{41}$ scenarios labeled as BG-2018mix and BG + CCS-2018mix, respectively. In particular, among the possible process configurations, the two BG scenarios consider the indirect gasification of biomass with steam fed to the gasifier. In addition to this, these cases assume that the electricity byproduct displaces electricity from the $2018 \mathrm{mix}$ (see Section 3.1 in the Supporting Information).

Finally, we also consider electrolytic water splitting based on $\mathrm{AE}^{42}$ and $\mathrm{PEM}^{43}$ electrolyzers powered by several sources. These sources include the current grid (PEM-2018mix/AE-2018mix), nuclear energy (PEM-NUCLEAR/AE-NUCLEAR), and renewable technologies, that is, photovoltaic (PEM-PV + 2018mix/AE-PV + 2018mix), wind (PEM-WIND + 2018mix/AE-WIND +2018mix), hydro (PEMHYDRO/AE-HYDRO), and biomass combustion with or without CCS (PEM-BECCS/AE-BECCS or PEM-BE/AE-BE, respectively). With respect to these last scenarios, we note that using bioenergy to produce $\mathrm{H}_{2}$ via water splitting is less efficient than directly implementing BG. However, this indirect route was added due to the expected future role of this power source in future sustainable energy scenarios. ${ }^{45}$ In the scenarios based on nondispatchable power sources, that is, wind and photovoltaic, we assume that these technologies supply energy only to the electrolyzer, while the grid covers the auxiliary needs of the HB process (i.e., compressors and pumps). This configuration ensures the full operability of the plant at all times. ${ }^{46}$

We consider additional electricity mixes projected under the sustainable development (2040SD) and stated policy (2040SP) scenarios to cover the electricity requirements of the primary process. ${ }^{45}$ Accordingly, we define the following scenarios: BG without CCS (BG-2040SDmix and BG-2040SPmix) and with CCS (BG + CCS-2040SDmix and BG + CCS-2040SPmix), water electrolysis entirely powered by the mix (PEM-2040SDmix/AE-2040SDmix and PEM-2040SPmix/AE-2040SPmix), water electrolysis powered by wind and where the mix supplies energy to the HB (PEM-WIND +2040 SDmix/AE-WIND + 2040SDmix and PEM-WIND + 2040SPmix/AE-WIND + 2040SPmix), and two analogous scenarios for solar photovoltaic (PEM-PV + 2040SDmix/AE-PV + 2040SDmix and PEM-PV + 2040SPmix/AE-PV + 2040SPmix).

In the three scenarios based on SMR, $\mathrm{N}_{2}$ is supplied within the air stream. ${ }^{39}$ In the scenarios not relying on SMR, cryogenic distillation provides high-purity $\mathrm{N}_{2}$ from the air. ${ }^{47}$ We omitted alternative technologies for air separation, for example, PSA or membranes, because they are either unsuitable for such large capacities or cannot meet the desired purity specifications, respectively. ${ }^{6,47}$

2.2. Life-Cycle Assessment and Planetary Boundaries Analysis. The environmental assessment follows the LCA guidelines described in the ISO 14040 and 14044 standards. ${ }^{48,49}$ The first LCA phase defines the goal and scope of the study. The goal of the environmental assessment is to quantify the absolute sustainability level of the alternative $\mathrm{NH}_{3}$ production routes. Hence, we defined the

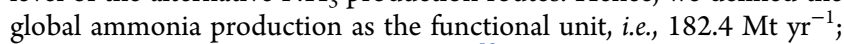
that is, world $\mathrm{NH}_{3}$ production in $2019 .{ }^{50}$ We adopted a cradle-to-gate scope using an attributional approach, encompassing all upstream activities and omitting further downstream conversion of $\mathrm{NH}_{3}$ into additional products. In the electrolysis scenarios, we assumed that the oxygen byproduct was vented, as done in previous studies. ${ }^{46}$ Regarding the BG scenario without CCS, we applied an avoided burden approach to deal with the electricity byproduct, which we modeled as an environmental credit.

In the second LCA phase, we modeled the life cycle inventories (LCIs) of the routes by combining the mass and energy flows retrieved from the Aspen-HYSYS simulations (foreground system) with the data of the background activities available in Ecoinvent v3.5 $5^{51}$ (accessed through SimaPro v9.0). ${ }^{52}$ The LCI of $\mathrm{H}_{2}$ was obtained by combining data from Ecoinvent and the literature. ${ }^{40-43}$ Additional details about the LCIs and process flowsheet models, with insights on their energy and water requirements, are provided in Sections 2 and 3 in the Supporting Information.

In the third phase of the LCA, we used the characterization factors proposed by Ryberg et al. ${ }^{53}$ to quantify the impact on the control variables of the PBs introduced by Rockström et al., ${ }^{33}$ who defined 11 control variables, each of them with a corresponding boundary, covering 9 Earth-system processes, namely, climate change, stratospheric ozone depletion, ocean acidification, biogeochemical flows of nitrogen and phosphorus, land system change, freshwater use, biosphere integrity, atmospheric aerosol loading, and introduction of novel entities. We omitted the latter two PBs because they have not been quantified yet. Climate change and biosphere integrity are regarded as core PBs, so they deserve special attention. ${ }^{34}$ However, a long-lasting transgression of any PB could lead to catastrophic events shifting the current state of the planet. Hence, all PBs together define the SOS for humanity.

To quantify the absolute sustainability performance of each route, we proceeded as follows (see also Figure S2). We first determined the impact of each scenario on the control variables of the PBs. Considering the set $\mathrm{B}$ of $\mathrm{PBs} \mathrm{b}$ and a set $\mathrm{S}$ of scenarios $\mathrm{s}$, the environmental impact for each scenario $s\left(\mathrm{EI}_{\mathrm{b}, \mathrm{s}}^{\mathrm{NH}_{3}}\right)$ was calculated according to eq 1

$$
\mathrm{EI}_{\mathrm{b}, \mathrm{s}}^{\mathrm{NH}_{3}}=\sum_{\mathrm{e} \in \mathrm{E}} \mathrm{LCI}_{\mathrm{e}, \mathrm{s}} \cdot \mathrm{CF}_{\mathrm{b}, \mathrm{e}} \cdot \mathrm{PV}_{\mathrm{NH}_{3}} \forall \mathrm{b} \in \mathrm{B}, \mathrm{s} \in \mathrm{S}
$$

where $\mathrm{LCI}_{e, s}$ represents the elementary flow e linked to the production of $1 \mathrm{~kg}$ of $\mathrm{NH}_{3}$ in scenario s. Note that the values of $\mathrm{LCI}_{\mathrm{e}, \mathrm{s}}$ are obtained in the second LCA phase (inventory analysis). Parameter $\mathrm{CF}_{\mathrm{b}, \mathrm{e}}$ denotes the characterization factor linked to $\mathrm{PB} \mathrm{b}$ for elementary flow e. These characterization factors were taken from Ryberg et al. ${ }^{54}$ for all PBs except for biosphere integrity, for which we used the impact factors developed by Hanafiah et al. ${ }^{55}$ and adapted by Galán-Martin et al. ${ }^{56} \mathrm{PV}^{\mathrm{NH}_{3}}$ denotes the production volume of $\mathrm{NH}_{3}$ in 2019.

With the impact on the control variables, we next computed the level of transgression (LT) attained by each scenario considering the share of the SOS (i.e., ecological budget delimited by the PBs) downscaled to $\mathrm{NH}_{3}$ production. The SOS, which limits the maximum perturbation that the Earth-system processes can sustain without compromising their long-term stability, is calculated as the difference between the boundary and the natural background level. The SOS should be shared among all anthropogenic activities. A range of sharing principles has been applied in the literature, and the most convenient way to perform this operation is the object of active debate. To allocate part of this budget to $\mathrm{NH}_{3}$ production, we applied an egalitarian downscaling based on the gross value added (GVA), as shown in eq 2, according to the principle that "it is unjust for individuals to be worse off than others" ${ }^{57}$

$$
\operatorname{SOS}_{\mathrm{b}}^{\mathrm{NH}_{3}}=\operatorname{SOS}_{\mathrm{b}}^{\mathrm{GLO}} \cdot \frac{\mathrm{GVA}^{\mathrm{NH} H_{3}}}{\mathrm{GVA}^{\mathrm{GLO}}} \leq \operatorname{SOS}_{\mathrm{b}}^{\mathrm{GLO}} \cdot \frac{\mathrm{GVA}^{\mathrm{CHEMS}}}{\mathrm{GVA}^{\mathrm{GLO}}} \forall \mathrm{b} \in \mathrm{B}
$$

where $\mathrm{SOS}_{\mathrm{b}}^{\mathrm{NH}_{3}}$ is the SOS downscaled to $\mathrm{NH}_{3}$ production for $\mathrm{PB} \mathrm{b}$, $\operatorname{SOS}_{\mathrm{b}}^{\mathrm{GLO}}$ is the global SOS for PB b, GVA ${ }_{3}^{\mathrm{NH}}$ is the GVA linked to $\mathrm{NH}_{3}$ production, and GVA ${ }^{\mathrm{GLO}}$ is the global GVA of all economic sectors together, estimated here at 70.06 trillion USD in 2017.58 Lacking public estimates for $\mathrm{GVA}^{\mathrm{NH}_{3}}$, we generated our main results for the total GVA of the chemical sector (i.e., GVA ${ }^{\text {CHEMS }}$ estimated at 5.71 trillion $\mathrm{USD}^{59}$ ), which accounts for the chemical industry's supply chain activities. This simplification overestimates the ecological budget allocated to $\mathrm{NH}_{3}$ production (i.e., the GVA of the chemical sector is given by all chemicals it produces, not only $\mathrm{NH}_{3}$ ) and, therefore, underestimates the LTs of the scenarios. This approach was chosen as the main one presented in this work since it is the most optimistic for the BAU. 


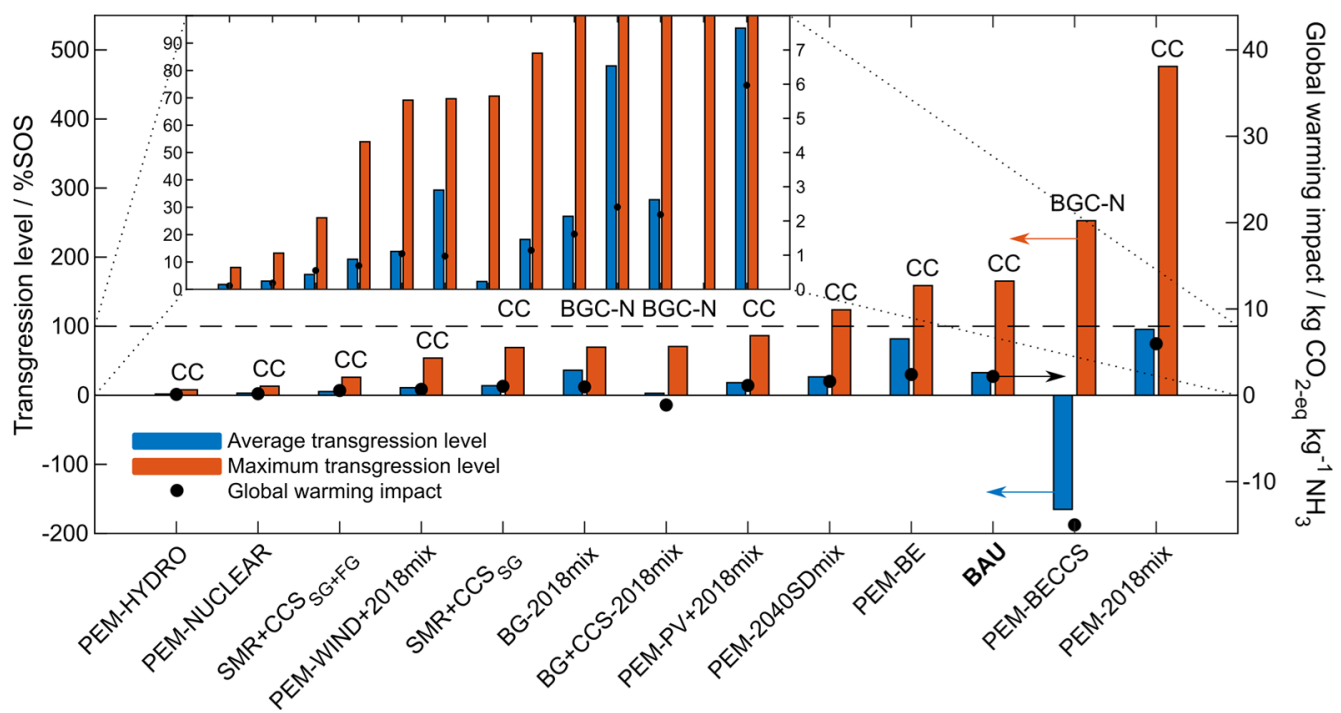

Figure 2. LT considering an egalitarian sharing principle based on the GVA of the chemical industry. The average LT is depicted with blue bars, while the maximum LT is depicted with orange bars (left axis), with the label above each orange bar denoting the PB showing the maximum transgression level (CC: climate change; BGC-N: biogeochemical flows-nitrogen). The scenarios are ordered according to the maximum LT. The black circles represent the global warming impact (GWI, right axis). The cases omitted in this figure are provided in Section 5.1.1 of the Supporting Information (Figure S3).

Alternatively, we also generated additional results considering a rough estimate for $\mathrm{GVA}^{\mathrm{NH}_{3}}$ (eq 3, results reported in Figures S4 and $S 7$ in the Supporting Information)

$$
\operatorname{SOS}_{\mathrm{b}}^{\mathrm{NH}_{3}^{\prime}}=\operatorname{SOS}_{\mathrm{b}}^{\mathrm{GLO}} \cdot \frac{\mathrm{GVA}^{\mathrm{CHEMS}}}{\mathrm{GVA}^{\mathrm{GLO}}} \cdot \frac{\mathrm{REV}^{\mathrm{NH}_{3}}}{\mathrm{REV}^{\mathrm{CHEMS}}} \forall \mathrm{b} \in \mathrm{B}
$$

where $\mathrm{SOS}_{\mathrm{b}}^{\mathrm{NH}_{3}{ }^{\prime}}$ is the SOS of the $\mathrm{NH}_{3}$ industry for $\mathrm{PB} \mathrm{b}$ according to the alternative downscaling, $\mathrm{SOS}_{\mathrm{b}}^{\mathrm{GLO}}$ and GVA ${ }^{\mathrm{GLO}}$ are defined as in eq 2, GVA ${ }^{\mathrm{CHEMS}}$ corresponds to the GVA associated with the chemical industry, ${ }^{59} \mathrm{REV}^{\mathrm{NH}_{3}}$ denotes the worldwide gross revenues associated to $\mathrm{NH}_{3}$ production, and $\mathrm{REV}^{\mathrm{CHEMS}}$ corresponds to the total revenues of the chemical industry in the world. While $\mathrm{REV}^{\mathrm{NH}_{3}}$ was extracted from the calculated production cost of the BAU scenario and the global ammonia production volume, the value for $\mathrm{REV}^{\mathrm{CHEMS}}$ was assumed equal to 1.10 trillion USD. ${ }^{59}$

Furthermore, alternative results were generated following a nonegalitarian approach (Figures $\mathrm{S} 5$ and $\mathrm{S} 8$ in the Supporting Information). Here, the downscaled SOS for each PB $\left(\operatorname{SOS}_{b}^{\mathrm{NH}_{3}{ }^{\prime \prime}}\right)$ was calculated as follows (eq 4)

$$
\operatorname{SOS}_{\mathrm{b}}^{\mathrm{NH}_{3}{ }^{\prime \prime}}=\operatorname{SOS}_{\mathrm{b}}^{\mathrm{GLO}} \cdot \frac{\mathrm{EI}_{\mathrm{b}, \mathrm{BAU}}^{\mathrm{NH}}}{\mathrm{EI}_{\mathrm{b}}^{\mathrm{GLO}}} \forall \mathrm{b} \in \mathrm{B}
$$

where $\operatorname{SOS}_{\mathrm{b}}^{\mathrm{GLO}}$ is the global SOS for the specific $\mathrm{PB} b$, while $\mathrm{EI}_{\mathrm{b}, \mathrm{BAU}}^{\mathrm{NH}_{3}}$ is the current global impact on critical Earth-system processes exerted by the $\mathrm{BAU} \mathrm{NH}_{3}$ production and $\mathrm{EI}_{\mathrm{b}}^{\mathrm{GLO}}$ is the current global anthropogenic impact on the same Earth-system processes. Hence, egalitarian approaches often assign a larger budget to those activities contributing more to the economy. In contrast, nonegalitarian sharing principles allocate larger quotas to those activities currently polluting more, which might be perceived as unfair. Each downscaling principle shows pros and cons, and the final choice should be consistent with the scope of the analysis. We note that ammonia plays a critical role in feeding a growing population, so, arguably, sharing principles leading to larger quotas might be more suitable.

Finally, we compared the environmental impact of $\mathrm{NH}_{3}$ production $\left(\mathrm{EI}_{\mathrm{b}, \mathrm{s}}^{\mathrm{NH}_{3}}\right)$ with its share of the SOS to compute the LT in each scenario (i.e., decarbonization route), as shown in eq 5

$$
\mathrm{LT}_{\mathrm{b}, \mathrm{s}}^{\mathrm{NH}_{3}}=\frac{\mathrm{EI}_{\mathrm{b}, \mathrm{s}}^{\mathrm{NH}_{3}}}{\mathrm{SOS}_{\mathrm{b}}^{\mathrm{NH}_{3}}} \forall \mathrm{b} \in \mathrm{B}, \mathrm{s} \in \mathrm{S}
$$

where the $\mathrm{LT}_{\mathrm{b}, \mathrm{s}}^{\mathrm{NH}_{3}}$ is given by the environmental impact associated with $\mathrm{NH}_{3}$ production $\left(\mathrm{EI}_{\mathrm{b}, \mathrm{s}}^{\mathrm{NH}_{3}}\right)$ divided by the share of the SOS for each $\mathrm{PB}$ $\mathrm{b}$ allocated to $\mathrm{NH}_{3}$ production $\left(\mathrm{SOS}_{\mathrm{b}}^{\mathrm{NH}_{3}}\right)$. A value of $\mathrm{LT}_{\mathrm{b}, \mathrm{s}}^{\mathrm{NH}_{3}}$ below $100 \%$ implies that the scenario does not exceed the ecological budget assigned to the system and, therefore, could be deemed sustainable for that PB. Conversely, if $\mathrm{LT}_{\mathrm{b}, \mathrm{s}}^{\mathrm{NH}_{3}}$ is greater than $100 \%$, then the scenario is unsustainable for that PB. Exceeding the ecological budget in at least one of the $\mathrm{PBs}$ implies that the scenario is unsustainable in absolute terms as transgressing one environmental limit suffices to compromise the resilience of the Earth system. In the assessment of scenarios, we considered both the maximum LT across all PBs as well as the average LT (details in the Supporting Information). Besides the PB metrics, for comparative purposes, we also quantified the ReCiPe $2016^{60}$ midpoint indicator "climate change" considering the Hierarchist perspective, often referred to as global warming impact or carbon footprint and expressed in $\mathrm{kg} \mathrm{CO}_{2 \text {-eq }}$ (Figure 2 as well as Figures S3-S5, and S16 in the Supporting Information).

Finally, in step four of the LCA methodology, the results are interpreted, and recommendations are made. Here, we analyzed the LTs of the scenarios to identify the main hotspots, compare their absolute sustainability performance, and determine whether they are truly sustainable.

2.3. Economic Assessment. The routes were compared in terms of total production cost, calculated as the summation of the OPEX and CAPEX expenditures. The OPEX term accounts for raw materials, utilities, labor, maintenance, property taxation, insurance, and land rent. The CAPEX term was estimated from the equipment cost, computed from the sizes of the process units provided by Aspen HYSYS, and the correlations and installation factors available in Towler and Sinnott. ${ }^{61}$ Finally, the levelized cost of $\mathrm{H}_{2}$ was calculated with the methodology and the factors provided in the Supporting Information.

\section{RESULTS AND DISCUSSION}

3.1. Planetary Boundaries Analysis. The AE scenar$\operatorname{ios}^{62,63}$ are discussed in the Supporting Information as the PEM technology holds better prospects. Moreover, among the scenarios relying on future mixes, only the most optimistic PEM-2040SD case is reported here, while the others are available in the Supporting Information. 


\begin{tabular}{|c|c|c|c|c|c|c|c|c|c|c|}
\hline \multirow{6}{*}{ 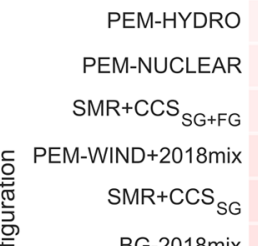 } & 8.0 & 7.7 & 1.5 & 2.6 & $<1$ & $<1$ & $<1$ & $<1$ & $<1$ & 400 \\
\hline & 13.2 & 13.2 & 1.1 & 4.2 & $<1$ & $<1$ & $<1$ & $<1$ & 1.9 & \multirow{2}{*}{200} \\
\hline & 26.1 & 26.0 & 2.8 & 8.4 & $<1$ & $<1$ & $<1$ & $<1$ & $<1$ & \\
\hline & 54.0 & 51.6 & 3.9 & 17.3 & 1.5 & $<1$ & $<1$ & $<1$ & $<1$ & 0 \\
\hline & 69.2 & 66.5 & 5.1 & 22.1 & $<1$ & $<1$ & $<1$ & $<1$ & $<1$ & \multirow[t]{2}{*}{-200} \\
\hline & 63.4 & 66.8 & 42.8 & 20.3 & 69.7 & $<1$ & $<1$ & 1.3 & 53.2 & \\
\hline$B G+C C S-2018 m i x$ & -115.9 & -102.2 & 33.7 & -37.1 & 70.6 & $<1$ & $<1$ & 1.4 & 53.7 & -400 \\
\hline PEM-PV+2018mix & 86.3 & 83.4 & 12.0 & 27.6 & 1.3 & $<1$ & $<1$ & $<1$ & $<1$ & \multirow[t]{2}{*}{-600} \\
\hline PEM-2040SDmix & 123.8 & 118.8 & 13.9 & 39.6 & 5.9 & $<1$ & $<1$ & $<1$ & 3.5 & \\
\hline PEM-BE & 149.9 & 158.8 & 94.4 & 47.9 & 151.4 & 2.0 & $<1$ & 3.3 & 116.0 & -800 \\
\hline BAU & 165.4 & 157.4 & 10.4 & 52.9 & $<1$ & $<1$ & $<1$ & $<1$ & $<1$ & -1000 \\
\hline PEM-BECCS & -1349.7 & -1245.1 & 68.9 & -431.6 & 252.8 & 3.3 & $<1$ & 5.7 & 193.7 & \multirow{2}{*}{-1200} \\
\hline PEM-2018mix & 476.1 & 452.6 & 31.5 & 152.2 & 5.6 & $<1$ & $<1$ & $<1$ & 2.6 & \\
\hline & $\mathrm{CC}-\mathrm{CO}_{2}$ & CC-EI & TBI & $\begin{array}{l}\text { OA } \\
\text { Plane }\end{array}$ & $\begin{array}{l}\text { BGC-N } \\
\text { ary boun }\end{array}$ & $\begin{array}{l}\text { BGC-P } \\
\text { laries }\end{array}$ & LSC & SOD & FWU & $\%$ \\
\hline
\end{tabular}

Figure 3. $\mathrm{LT}$ in terms of percentage of the SOS assigned to the chemical industry for each of the nine studied control variables. $\mathrm{CC}_{-} \mathrm{CO}_{2}$ : climate change- $\mathrm{CO}_{2}$ concentration; CC-EI: climate change-energy imbalance; TBI: terrestrial biosphere integrity; OA: ocean acidification; BGC-N: biogeochemical flows-nitrogen; BGC-P: biogeochemical flows-phosphorus; LSC: land system change; SOD: stratospheric ozone depletion; FWU: freshwater use. The cases omitted in this figure are provided in Section 5.1.1 of the Supporting Information (Figure S6).

Figure 2 shows the average LT (across all PBs), the maximum LT, and the global warming impact, where the scenarios are sorted according to the maximum LT. PEM electrolysis powered by hydropower (PEM-HYDRO) emerges as the best route, followed by the same technology powered by nuclear (PEM-NUCLEAR) and then SMR with CCS for both syngas and furnace flue gas $\left(\mathrm{SMR}+\mathrm{CCS}_{\mathrm{SG}+\mathrm{FG}}\right)$. Five scenarios are unsustainable, including the BAU fossil $\mathrm{NH}_{3}$ (BAU) and the PEM scenarios powered by biomass (BECCS or BE) or the current or future (decarbonized) mix (2018mix and 2040SDmix, respectively). Indeed, these scenarios exceed the SOS allocated to the whole chemical sector in at least one PB (i.e., climate change for PEM-2040SDmix, PEM-BE, BAU, and PEM-2018mix and the nitrogen flow for PEM-BECCS). Notably, despite its negative carbon footprint, PEM powered by BECCS (PEM-BECCS) is the second-worst scenario in terms of maximum LT (after PEM-2018mix) due to its poor performance in the biogeochemical flow of nitrogen $(252.8 \%$ of the assigned SOS). BG with or without CCS also shows its highest LT in this Earth-system process, while in the other scenarios, the most critical impact always corresponds to climate change.

In general terms, the carbon footprint (black circles in Figure 2) follows the same pattern as the maximum LT because the largest transgression often corresponds to the climate change $\mathrm{PB}$, strongly linked to carbon emissions. However, this trend does not apply to the biomass routes with CCS, which show very low carbon footprints but a high impact on the nitrogen flow PB (where they perform worse than in climate change). Hence, these scenarios clearly highlight the pitfalls of myopic assessments focused only on carbon emissions. Following this carbon oriented approach, the best scenario would be PEM-BECCS, followed by BG + CCS2018mix, and then PEM-HYDRO, where the first two show a net-negative carbon balance $\left(-15.00\right.$ and $-1.12 \mathrm{~kg} \mathrm{CO}_{2-\mathrm{eq}} \mathrm{kg}$ $\mathrm{NH}_{3}{ }^{-1}$, respectively, on a cradle-to-gate basis).

The average LT follows a different pattern, with the best scenario being PEM-BECCS, followed by PEM-HYDRO, and then BG + CCS-2018mix (-165.1, 1.8, and 2.9\%, respectively). Focusing on the PEM scenarios, hydropower shows the lowest positive average LT, followed by nuclear, wind, and solar (1.8, 3.0, 11.0, and $18.2 \%$, respectively). In contrast, bioenergy without CCS shows the second-highest average impact after PEM powered by the current grid mix (81.7 and 95.5\%, respectively). Using decarbonized electricity in the PEM-2040SDmix scenario substantially improves the environmental performance $(26.7 \%)$ but not enough to outperform the SMR + $\mathrm{CCS}_{\mathrm{SG}+\mathrm{FG}}(5.4 \%) \cdot \mathrm{H}_{2}$ from $\mathrm{BG}$ performs worse than the BAU (36.3 vs $32.8 \%$ ).

Figure 3 displays the LTs attained by the studied scenarios in each Earth-system process. The LT varies substantially across scenarios in the carbon-related PBs, that is, climate change and ocean acidification, from as low as $-1350 \%$ (PEMBECCS, climate change-atmospheric $\mathrm{CO}_{2}$ concentration) to as high as $476 \%$ (PEM-2018mix, climate change-atmospheric $\mathrm{CO}_{2}$ concentration). The BAU, PEM-2018mix, PEM2040SDmix, and PEM-BE cases transgress the two climate change related control variables, while ocean acidification is only transgressed by the PEM-2018mix scenario.

None of the scenarios transgresses the terrestrial biosphere integrity $\mathrm{PB}$, although those based on biomass lead to large impacts on this Earth-system process (i.e., BG-2018mix, BG + CCS-2018mix, PEM-BE, and PEM-BECCS). This poorer performance is due to their land-use requirements linked to biomass growth, acting as a significant biosphere integrity stressor. These biomass scenarios also perform poorly in the nitrogen flow and freshwater use PBs, with those based on bioenergy with and without CCS transgressing both of them. By contrast, the other scenarios show low LTs in these PBs ( $<32 \%$ in biosphere integrity, $<6 \%$ in the nitrogen flow, and $<4 \%$ in freshwater use). All scenarios perform well in the phosphorus flow and land system change PBs (always $<4 \%$ and in most cases $<1 \%$ ), both connected to agriculture activities. ${ }^{64}$ Likewise, all scenarios show low impacts on the stratospheric ozone depletion $\mathrm{PB}$, with LTs below $6 \%$.

The alternative downscaling based on a rough estimate of the GVA of $\mathrm{NH}_{3}$ production (Figure S4) would considerably reduce its allowable ecological budget (i.e., from $8.1 \%$ of the SOS to $0.2 \%$ in the new case); as a result, no single scenario would be environmentally sustainable. However, the relative 


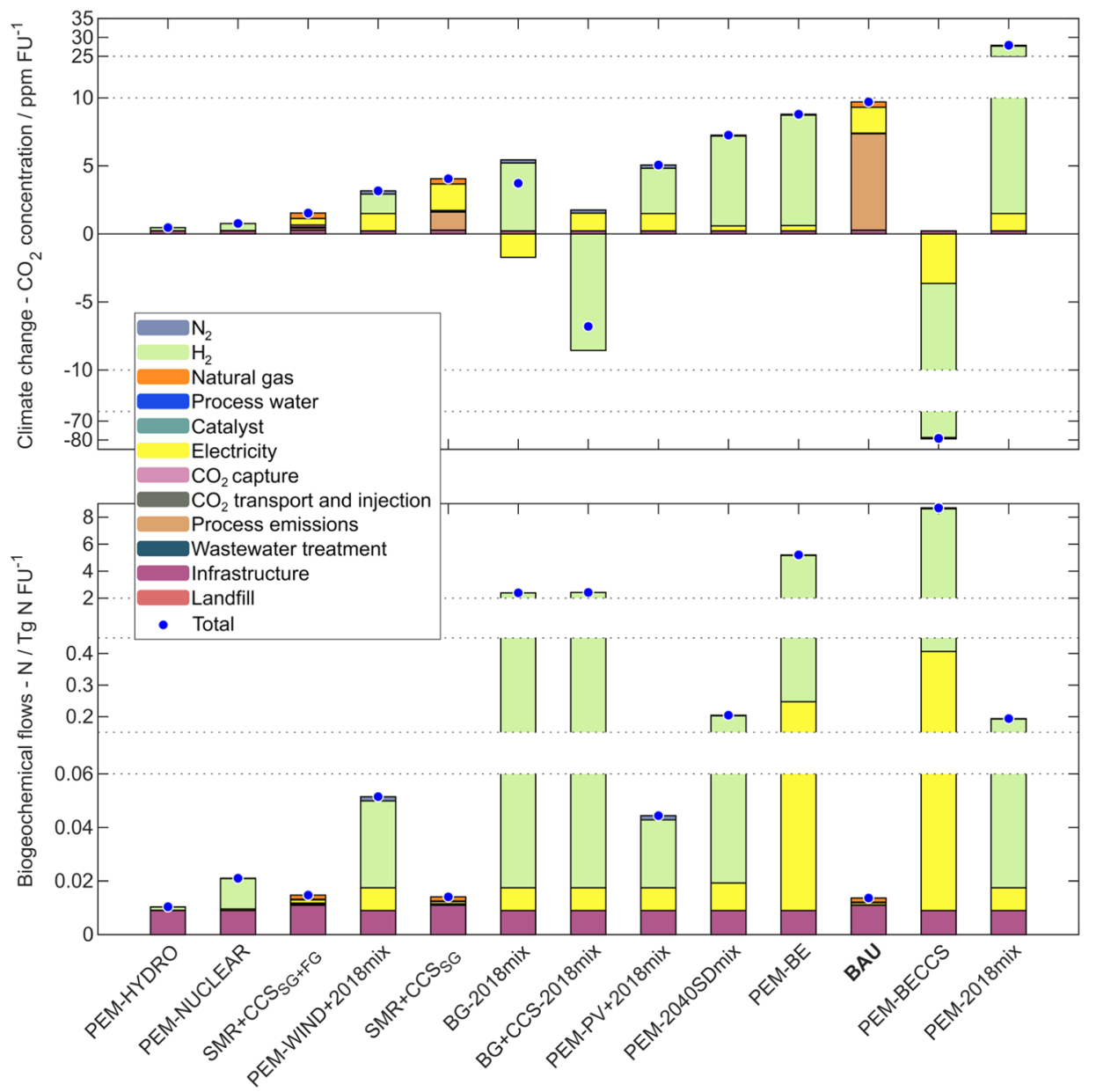

Figure 4. Breakdown of impacts for the control variables climate change- $\mathrm{CO}_{2}$ concentration (top) and biogeochemical flows-nitrogen (bottom). The total impact is shown in blue circles. The cases omitted in this figure, as well as the PBs not shown here, are provided in Section 5.1.2 of the Supporting Information (Figures S9-S15). The electrolytic hydrogen accounts for the electricity consumed in the electrolyzer for water

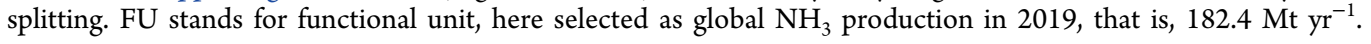

ranking of all technologies in terms of maximum LT would remain unaltered since the allowable budget would decrease to the same extent across all scenarios. Moreover, this alternative downscaling approach would lead to much larger LTs in all PBs (Figure S7). Here, land system change would be the only $\mathrm{PB}$ that is not transgressed across all scenarios, while the others would be transgressed by at least one route. Notably, the climate change $\mathrm{PBs}$ would now be transgressed by all scenarios except for those based on biomass.

The nonegalitarian downscaling (Figure S5) would also decrease the share of the SOS assigned to $\mathrm{NH}_{3}$ production but this time unevenly (e.g., $1.4 \times 10^{-4} \%$ of the SOS in landsystem change and $0.9 \%$ in climate change, $\mathrm{CO}_{2}$ concentration). As a result, all scenarios would also exceed at least one $\mathrm{PB}$, with PEM-HYDRO showing the lowest maximum LT (in climate change) and PEM-BECCS the largest transgression (in the nitrogen flow). This downscaling approach shifts the maximum LT category for several scenarios, that is, the worst performance in PEM-NUCLEAR now corresponds to freshwater use (instead of the nitrogen flow) and to the phosphorus flow (instead of the nitrogen PB) for the PEM-2040SDmix and PEM-PV $+2018 \mathrm{mix}$ cases. This behavior is due to the very stringent targets on the $\mathrm{PBs}$ where the impact of fossil $\mathrm{NH}_{3}$ is marginal in absolute terms. For example, in the standard egalitarian downscaling, the share of the SOS in freshwater is
$8.1 \%$ (Figure S8). By contrast, in the nonegalitarian, this value is $1.8 \times 10^{-2} \%$ as $\mathrm{NH}_{3}$ production contributes marginally to the global freshwater consumption (linked to agriculture activities). In terms of average LT, all scenarios would exceed the SOS except for PEM-HYDRO. Furthermore, all scenarios in the nonegalitarian downscaling case would now transgress the biogeochemical flows, where the global impact of fossil $\mathrm{NH}_{3}$ (on a cradle-to-gate basis) is negligible, resulting in very stringent quotas.

Figure 4 provides the breakdown of impact in those PBs showing the highest LTs across the scenarios, that is, climate change-atmospheric $\mathrm{CO}_{2}$ concentration and the nitrogen flow (other breakdowns in Section 5.1.2 in the Supporting Information). The main contributions to the climate change category in the BAU are linked to the direct $\mathrm{CO}_{2}$ emissions and the electricity and natural gas inputs $(73.0,19.5$, and $4.0 \%$ for BAU, 32.7, 47.8, and 9.6\% for SMR + $\mathrm{CCS}_{\mathrm{SG}}$, and 9.9, 31.4, and $25.3 \%$ for $\mathrm{SMR}+\mathrm{CCS}_{\mathrm{SG}+\mathrm{FG}}$, respectively). Hence, capturing the $\mathrm{CO}_{2}$ emissions from the SMR plant is an effective strategy to reduce the climate change impact.

On the other hand, $\mathrm{H}_{2}$ is the main contributor to climate change in the PEM scenarios due to the high electricity demand for water splitting (i.e., 45.4 to $94.3 \%$ of the total impact), often followed by the electricity needs of the plant (2.0-40.1\% share). $\mathrm{H}_{2}$ is also the main contributor to climate 


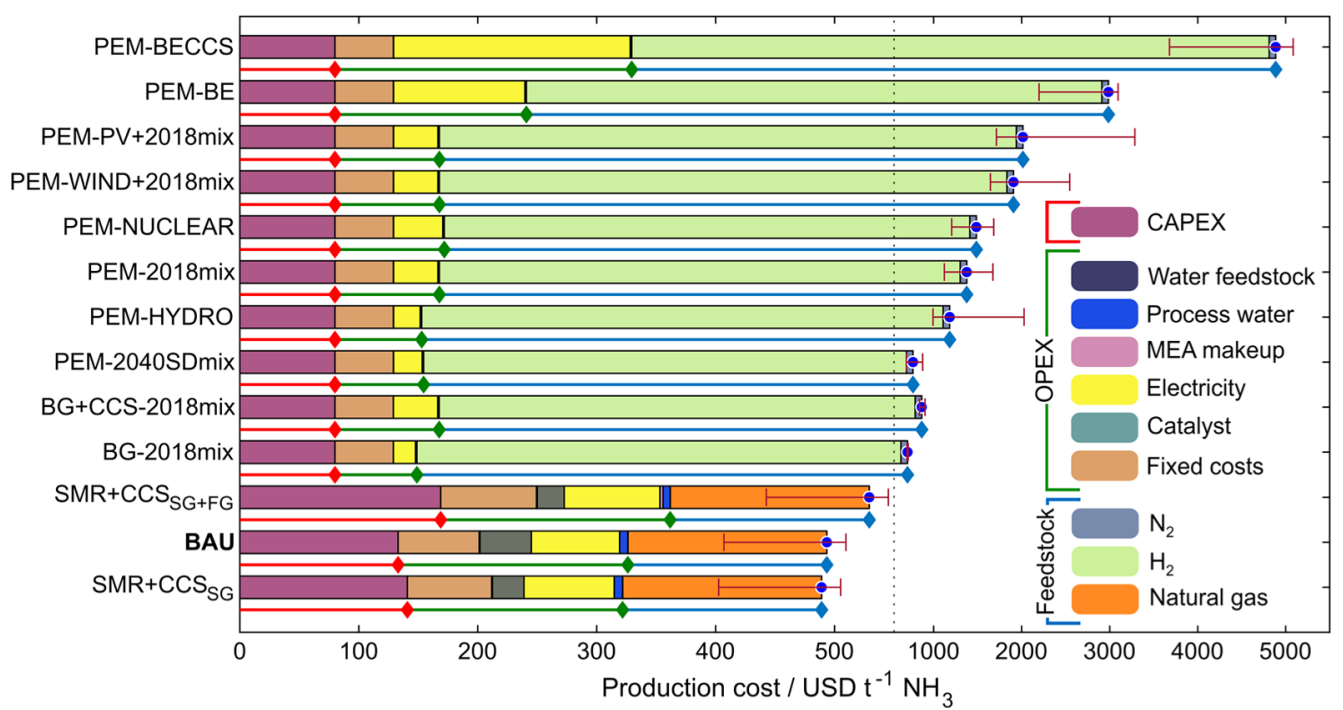

Figure 5. Total production cost breakdown for the selected scenarios. The cases omitted in this figure are provided in Section 5.2 of the Supporting Information (Figure S17). The uncertainty bars show the best- and worst-case scenario, computed as described in the Supporting Information.

change in the biomass scenarios, two of which show negative impacts on climate change (i.e., PEM-BECCS and BG + CCS2018mix) due to the negative carbon balance linked to the $\mathrm{H}_{2}$ source. The BG-2018mix scenario shows a negative contribution from electricity and a positive one from $\mathrm{H}_{2}$ since electricity coproduction was modeled as an environmental credit. By contrast, the opposite happens in the BG + CCS$2018 \mathrm{mix}$ scenario, where the carbon capture unit consumes electricity, leading to a net positive consumption rate.

With regard to the nitrogen flow, $\mathrm{H}_{2}$ represents, again, the main contribution (share of 94.4 to $99.2 \%$ in the biomass scenarios, i.e., BG and PEM powered with electricity from bioenergy with and without CCS), followed by electricity (0.3-4.6\% of the total). The high impact of $\mathrm{H}_{2}$ is here linked to the biomass needed to produce either $\mathrm{H}_{2}$ or electricity. The biomass source corresponds to a poplar feedstock, with high requirements in terms of fertilizers.

3.2. Economic Assessment. Figure 5 shows the results of the economic analysis. No single scenario would outperform the BAU (increments in production cost in the range 42.4890.3\%). BG-2018mix emerges as the cheapest green $\mathrm{H}_{2}$ scenario, and PEM-BECCS is the most expensive.

Coupling CCS with the BAU process decreases the costs marginally in the scenario $\mathrm{SMR}+\mathrm{CCS}_{\mathrm{SG}}(-0.01 \%)$ while increasing it by $7.2 \%$ in the $\mathrm{SMR}+\mathrm{CCS}_{\mathrm{SG}+\mathrm{FG}}$. The $\mathrm{SMR}+$ $\mathrm{CCS}_{\mathrm{SG}}$ cost slightly changes (with respect to BAU) due to the trade-off between a higher investment in compressors and lower disposal costs due to lower emissions (30 USD t ${ }^{-1} \mathrm{CO}_{2}$, Supporting Information for additional details). Among the PEM electrolysis scenarios, the case powered by the 2040SD mix is the cheapest, that is, $44.4 \%$ cheaper than the same technology powered by the current energy mix (PEM2018mix). The hydropower and PEM-2018mix scenarios follow after the PEM-2040SDmix. The highest production costs correspond to BECCS, where CCS increases the production cost by $63.7 \%$ compared to the non-CCS case. The scenarios based on BG with and without CCS are the fourth and sixth most profitable scenarios, with a total increment in the production cost of $42.3 \%$ and $75.1 \%$ (relative to BAU), respectively.
The main conclusion that can be extracted from Figure 5 is that the largest contributor to the costs of the green $\mathrm{H}_{2}$ scenarios is $\mathrm{H}_{2}$ production (i.e., $68.2-91.7 \%$ of the total cost). In the PEM and $\mathrm{AE}$ scenarios, the $\mathrm{H}_{2}$ cost is strongly linked to the cost of electricity, which varies with the location of the solar and wind power facility. Here, global average values of 0.0856 and $0.0564 \mathrm{USD} \mathrm{kWh}^{-1}$ were assumed for solar and wind, respectively; see Section 4.1 in the Supporting Information for additional details. According to the observations here reported, considering the future improvements in energy efficiency and the increasing penetration of cheaper renewable power sources, deploying standalone plants relying on $\mathrm{H}_{2}$ from renewable-powered electrolysis could lead to competitive scenarios with respect to the BAU.

\section{CONCLUSIONS}

This work assessed, for the first time to the best of the authors' knowledge, the absolute sustainability performance of lowcarbon HB ammonia synthesis routes based on BG, water electrolysis, and CCS coupled with the BAU. We quantified the impact of these scenarios on seven Earth-system processes and carried out a techno-economic assessment to shed further light on their feasibility.

We found that the conventional fossil ammonia is unsustainable as it significantly transgresses the climate change $\mathrm{PB}$, while alternative routes could substantially improve the absolute sustainability level of fossil $\mathrm{NH}_{3}$ to different extents according to the sharing principle. Scenarios based on water electrolysis powered by wind, solar, nuclear, and hydropower and CCS coupled to the BAU are particularly appealing. Among them, ammonia from $\mathrm{H}_{2}$ produced via PEM electrolysis with hydropower is the most sustainable option, while the same technology powered by the current mix, yet to be decarbonized, is the worst performer. However, the assumption of complete dispatchability of hydropower depends on the specific location. In practice, the large-scale deployment of this technology will be constrained by geographic factors, given the nonuniform distribution of water availability. Scenarios with lower carbon footprints tend to perform better in the studied PBs (in terms of maximum transgression level) because the largest impacts 
often occur in the climate change PB (strongly linked to carbon emissions). Biomass scenarios with CCS, however, perform very well in climate change, even attaining carbonnegative footprints, but poorly in other categories, for example, biosphere integrity, nitrogen flow, and freshwater use. This behavior is due to the substantial amounts of land, fertilizers, and water linked to biomass growth. Moreover, $\mathrm{N}_{2}$ plays a minor role in the PEM- and biomass-based scenarios. Consequently, other technologies for procuring nitrogen, such as air separation through more energy-efficient technologies than cryogenic distillation, might lead to similar results.

Burden-shifting (i.e., exacerbating some impacts when attempting to improve others, e.g., climate change impacts) is negligible in the PEM scenarios not relying on bioenergy. In contrast, BG and PEM electrolysis powered by bioenergy improve climate change at the expense of significantly damaging the biosphere integrity, nitrogen flow, and freshwater use.

The high cost of green $\mathrm{H}_{2}$ makes environmentally superior strategies such as PEM electrolysis and gasification economically unappealing. Deploying CCS in the BAU process emerges as a cost-effective strategy to reduce the climate change impact of fossil ammonia. However, the limited storage capacity and public acceptance issues represent significant obstacles.

We found that the downscaling approach can critically affect the absolute sustainability of the analyzed routes, to the point that no single scenario might be sustainable for some sharing principles. Hence, cooperation across economic sectors will be needed for operating safely (and collectively) within the SOS. Notably, the excess in impact quota of the ammonia process could be offset by other sectors to sustainably cover the fertilizers' demand needed to feed a growing population. In the climate change PBs, this excess of quota could also be handled by removing carbon from the air via net negative emission technologies and practices, such as direct air capture. In parallel, a distributed scheme based on small- or medium-scale plants also based on low-carbon strategies may exhibit complementary advantages and restrictions, adding a distinct tool toward developing sustainable and profitable fertilizer production. Moreover, preventing the transgression of the PBs strongly linked to agriculture activities may require dietary changes. Notably, the EAT-Lancet Commission already proposed a sustainable diet to preserve planetary health. ${ }^{65}$ Optimizing the nitrogen use efficiency in crop production ${ }^{66}$ and recovering nutrients from organic wastes ${ }^{67}$ could also help to operate within the PBs.

Overall, this work highlights the need to consider absolute environmental sustainability metrics beyond the conventional carbon footprint to evaluate alternative decarbonization routes. For the case of $\mathrm{NH}_{3}$ production, we show that while some scenarios are superior in absolute sustainability terms, they are not likely to become economically competitive in the short-tomiddle term. Therefore, further experimental research and governmental incentives are needed to drive down the production cost of the greener routes, which should be underpinned by environmental studies of the type presented herein.

\section{ASSOCIATED CONTENT}

\section{Supporting Information}

The Supporting Information is available free of charge at https://pubs.acs.org/doi/10.1021/acssuschemeng.1c01915.

Modeling details for the processes modeled in Aspen HYSYS, life cycle inventories, additional details on the PB methodology, assumptions behind the levelized cost of hydrogen, additional details about CAPEX calculations, additional environmental assessment metrics, and environmental and economic assessment of all scenarios, including those omitted in the main manuscript (PDF)

\section{AUTHOR INFORMATION}

\section{Corresponding Authors}

Javier Pérez-Ramírez - Institute for Chemical and Bioengineering, Department of Chemistry and Applied Biosciences, ETH Zurich, 8093 Zurich, Switzerland; ○ orcid.org/0000-0002-5805-7355; Email: jpr@ chem.ethz.ch

Gonzalo Guillén-Gosálbez - Institute for Chemical and Bioengineering, Department of Chemistry and Applied Biosciences, ETH Zurich, 8093 Zurich, Switzerland; ○ orcid.org/0000-0001-6074-8473; Email: gonzalo.guillen.gosalbez@chem.ethz.ch

\section{Authors}

Sebastiano Carlo D'Angelo - Institute for Chemical and Bioengineering, Department of Chemistry and Applied Biosciences, ETH Zurich, 8093 Zurich, Switzerland

Selene Cobo - Institute for Chemical and Bioengineering, Department of Chemistry and Applied Biosciences, ETH Zurich, 8093 Zurich, Switzerland

Victor Tulus - Institute for Chemical and Bioengineering, Department of Chemistry and Applied Biosciences, ETH Zurich, 8093 Zurich, Switzerland

Abhinandan Nabera - Institute for Chemical and Bioengineering, Department of Chemistry and Applied Biosciences, ETH Zurich, 8093 Zurich, Switzerland

Antonio José Martín - Institute for Chemical and Bioengineering, Department of Chemistry and Applied Biosciences, ETH Zurich, 8093 Zurich, Switzerland

Complete contact information is available at: https://pubs.acs.org/10.1021/acssuschemeng.1c01915

\section{Notes}

The authors declare no competing financial interest.

\section{ACKNOWLEDGMENTS}

This publication was created as part of NCCR Catalysis, a National Centre of Competence in Research funded by the Swiss National Science Foundation.

\section{REFERENCES}

(1) Apodaca, L. E. Mineral Commodity Summaries 2019: Nitrogen (Fixed)-Ammonia; U.S. Geological Survey: Lakewood, CO, 2019.

(2) Wiley-VCH Verlag GmbH. Appl, M Ammonia, 1. Introduction. In Ullmann's Encyclopedia of Industrial Chemistry; Wiley-VCH Verlag GmbH \& Co. KGaA: Weinheim, Germany, 2011.

(3) Wiley-VCH Verlag GmbH. Appl M Ammonia, 2. Production Processes. In Ullmann's Encyclopedia of Industrial Chemistry; WileyVCH Verlag GmbH \& Co. KGaA: Weinheim, Germany, 2011. 
(4) Arora, P.; Hoadley, A. F. A.; Mahajani, S. M.; Ganesh, A. SmallScale Ammonia Production from Biomass: A Techno-EnviroEconomic Perspective. Ind. Eng. Chem. Res. 2016, 55, 6422-6434.

(5) Levi, P. G.; Cullen, J. M. Mapping Global Flows of Chemicals: From Fossil Fuel Feedstocks to Chemical Products. Environ. Sci. Technol. 2018, 52, 1725-1734.

(6) Smith, C.; Hill, A. K.; Torrente-Murciano, L. Current and Future Role of Haber-Bosch Ammonia in a Carbon-Free Energy Landscape. Energy Environ. Sci. 2020, 13, 331-344.

(7) Emissions by sector- Our World in Data https:// ourworldindata.org/emissions-by-sector\#annual-co2-emissions-bysector (accessed Mar 4, 2021).

(8) Bicer, Y.; Dincer, I.; Vezina, G.; Raso, F. Impact Assessment and Environmental Evaluation of Various Ammonia Production Processes. Environ. Manag. 2017, 59, 842-855.

(9) Dincer, I.; Bicer, Y. Ammonia Production. In Comprehensive Energy Systems; Dincer, I., Ed.; Elsevier: Oxford, 2018; Vol. 3, pp 4194.

(10) Frattini, D.; Cinti, G.; Bidini, G.; Desideri, U.; Cioffi, R.; Jannelli, E. A System Approach in Energy Evaluation of Different Renewable Energies Sources Integration in Ammonia Production Plants. Renewable Energy 2016, 99, 472-482.

(11) Sánchez, A.; Martín, M.; Vega, P. Biomass Based Sustainable Ammonia Production: Digestion vs Gasification. ACS Sustain. Chem. Eng. 2019, 7, 9995-10007.

(12) Martín, A. J.; Shinagawa, T.; Pérez-Ramírez, J. Electrocatalytic Reduction of Nitrogen: From Haber-Bosch to Ammonia Artificial Leaf. Chem 2019, 5, 263-283.

(13) MacFarlane, D. R.; Cherepanov, P. V.; Choi, J.; Suryanto, B. H. R.; Hodgetts, R. Y.; Bakker, J. M.; Ferrero Vallana, F. M.; Simonov, A. N. A Roadmap to the Ammonia Economy. Joule 2020, 4, 1186-1205.

(14) Andersen, S. Z.; Čolić, V.; Yang, S.; Schwalbe, J. A.; Nielander, A. C.; McEnaney, J. M.; Enemark-Rasmussen, K.; Baker, J. G.; Singh, A. R.; Rohr, B. A.; Statt, M. J.; Blair, S. J.; Mezzavilla, S.; Kibsgaard, J.; Vesborg, P. C. K.; Cargnello, M.; Bent, S. F.; Jaramillo, T. F.; Stephens, I. E. L.; Nørskov, J. K.; Chorkendorff, I. A Rigorous Electrochemical Ammonia Synthesis Protocol with Quantitative Isotope Measurements. Nature 2019, 570, 504-508.

(15) Ioannou, I.; D’Angelo, S. C.; Galán-Martín, Á.; Pozo, C.; PérezRamírez, J.; Guillén-Gosálbez, G. Process Modelling and Life Cycle Assessment Coupled with Experimental Work to Shape the Future Sustainable Production of Chemicals and Fuels. React. Eng. Technol. 2021, DOI: 10.1039 /d0re00451k.

(16) Kleinekorte, J.; Fleitmann, L.; Bachmann, M.; Kätelhön, A.; Barbosa-Póvoa, A.; von der Assen, N.; Bardow, A. Life Cycle Assessment for the Design of Chemical Processes, Products, and Supply Chains. Annu. Rev. Chem. Biomol. Eng. 2020, 11, 203-233.

(17) Guillén-Gosálbez, G.; You, F.; Galán-Martín, Á.; Pozo, C.; Grossmann, I. E. Process Systems Engineering Thinking and Tools Applied to Sustainability Problems: Current Landscape and Future Opportunities. Curr. Opin. Chem. Eng. 2019, 26, 170-179.

(18) Grossmann, I. E.; Harjunkoski, I. Process Systems Engineering: Academic and Industrial Perspectives. Comput. Chem. Eng. 2019, 126, 474-484.

(19) Wolf, M.-A.; Pant, R.; Chomkhamsri, K.; Sala, S.; Pennington, D. Life Cycle Data System (ILCD) Handbook The International Reference Towards More Sustainable Production and Consumption for a Resource-Efficient Europe; European Commission Joint Research Centre, Luxembourg, 2012.

(20) Gomez, J. R.; Baca, J.; Garzon, F. Techno-Economic Analysis and Life Cycle Assessment for Electrochemical Ammonia Production Using Proton Conducting Membrane. Int. J. Hydrogen Energy 2020, 45, 721-737.

(21) Young, B.; Krynock, M.; Carlson, D.; Hawkins, T. R.; Marriott, J.; Morelli, B.; Jamieson, M.; Cooney, G.; Skone, T. J. Comparative Environmental Life Cycle Assessment of Carbon Capture for Petroleum Refining, Ammonia Production, and Thermoelectric Power Generation in the United States. Int. J. Greenhouse Gas Control 2019, 91, 102821.
(22) Sadeek, S.; Chan, T. L.; Ramdath, R.; Rajkumar, A.; Guo, M.; Ward, K. The Influence of Raw Material Availability and Utility Power Consumption on the Sustainability of the Ammonia Process. Chem. Eng. Res. Des. 2020, 158, 177-192.

(23) Tock, L.; Maréchal, F.; Perrenoud, M. Thermo-Environomic Evaluation of the Ammonia Production. Can. J. Chem. Eng. 2015, 93, $356-362$.

(24) Bicer, Y.; Dincer, I.; Zamfirescu, C.; Vezina, G.; Raso, F. Comparative Life Cycle Assessment of Various Ammonia Production Methods. J. Clean. Prod. 2016, 135, 1379-1395.

(25) Bicer, Y.; Dincer, I. Assessment of a Sustainable Electrochemical Ammonia Production System Using Photoelectrochemically Produced Hydrogen under Concentrated Sunlight. ACS Sustain. Chem. Eng. 2017, 5, 8035-8043.

(26) Bicer, Y.; Dincer, I. Life Cycle Assessment of Nuclear-Based Hydrogen and Ammonia Production Options: A Comparative Evaluation. Int. J. Hydrogen Energy 2017, 42, 21559-21570.

(27) Castellani, B.; Rinaldi, S.; Morini, E.; Nastasi, B.; Rossi, F. Flue Gas Treatment by Power-to-Gas Integration for Methane and Ammonia Synthesis-Energy and Environmental Analysis. Energy Convers. Manag. 2018, 171, 626-634.

(28) Demirel, Y.; Alhajji, M. H.; Demirel, Y. Technoeconomics and Sustainability of Renewable Methanol and Ammonia Productions Using Wind Power-Based Hydrogen. J. Adv. Chem. Eng. 2015, 5, 3.

(29) Tallaksen, J.; Bauer, F.; Hulteberg, C.; Reese, M.; Ahlgren, S. Nitrogen Fertilizers Manufactured Using Wind Power: Greenhouse Gas and Energy Balance of Community-Scale Ammonia Production. J. Clean. Prod. 2015, 107, 626-635.

(30) Gilbert, P.; Alexander, S.; Thornley, P.; Brammer, J. Assessing Economically Viable Carbon Reductions for the Production of Ammonia from Biomass Gasification. J. Clean. Prod. 2014, 64, 581589

(31) Mora, M. A. M.; Vergara, C. P.; Leiva, M. A.; Martínez Delgadillo, S. A.; Rosa-Domínguez, E. R. Life Cycle Assessment of Carbon Capture and Utilization from Ammonia Process in Mexico. J. Environ. Manage. 2016, 183, 998-1008.

(32) Bjørn, A.; Chandrakumar, C.; Boulay, A.-M.; Doka, G.; Fang, K.; Gondran, N.; Hauschild, M. Z.; Kerkhof, A.; King, H.; Margni, M.; McLaren, S.; Mueller, C.; Owsianiak, M.; Peters, G.; Roos, S.; Sala, S.; Sandin, G.; Sim, S.; Vargas-Gonzalez, M.; Ryberg, M. Review of LifeCycle Based Methods for Absolute Environmental Sustainability Assessment and Their Applications. Environ. Res. Lett. 2020, 15, 083001.

(33) Rockström, J.; Steffen, W.; Noone, K.; Persson, Å.; Chapin, F. S.; Lambin, E. F.; Lenton, T. M.; Scheffer, M.; Folke, C.; Schellnhuber, H. J.; Nykvist, B.; De Wit, C. A.; Hughes, T.; Van Der Leeuw, S.; Rodhe, H.; Sörlin, S.; Snyder, P. K.; Costanza, R.; Svedin, U.; Falkenmark, M.; Karlberg, L.; Corell, R. W.; Fabry, V. J.; Hansen, J.; Walker, B.; Liverman, D.; Richardson, K.; Crutzen, P.; Foley, J. A. A Safe Operating Space for Humanity. Nature 2009, 461, $472-475$

(34) Steffen, W.; Richardson, K.; Rockström, J.; Cornell, S. E.; Fetzer, I.; Bennett, E. M.; Biggs, R.; Carpenter, S. R.; De Vries, W.; De Wit, C. A.; Folke, C.; Gerten, D.; Heinke, J.; Mace, G. M.; Persson, L. M.; Ramanathan, V.; Reyers, B.; Sörlin, S. Planetary Boundaries: Guiding Human Development on a Changing Planet. Science 2015, 347, 1259855.

(35) Lade, S. J.; Steffen, W.; de Vries, W.; Carpenter, S. R.; Donges, J. F.; Gerten, D.; Hoff, H.; Newbold, T.; Richardson, K.; Rockström, J. Human Impacts on Planetary Boundaries Amplified by Earth System Interactions. Nat. Sustain. 2020, 3, 119-128.

(36) González-Garay, A.; Frei, M. S.; Al-Qahtani, A.; Mondelli, C.; Guillén-Gosálbez, G.; Pérez-Ramírez, J. Plant-to-Planet Analysis of $\mathrm{CO}_{2}$-Based Methanol Processes. Energy Environ. Sci. 2019, 12, 34253436.

(37) Wheeler, J.; Galán-Martín, Á.; Mele, F. D.; Guillén-Gosálbez, G. Designing Biomass Supply Chains within Planetary Boundaries. AIChE J. 2021, 67, No. e17131. 
(38) Araújo, A.; Skogestad, S. Control Structure Design for the Ammonia Synthesis Process. Comput. Chem. Eng. 2008, 32, 29202932.

(39) Luyben, W. L. Plantwide Control of a Coupled Reformer/ Ammonia Process. Chem. Eng. Res. Des. 2018, 134, 518-527.

(40) Susmozas, A.; Iribarren, D.; Dufour, J. Life-Cycle Performance of Indirect Biomass Gasification as a Green Alternative to Steam Methane Reforming for Hydrogen Production. Int. J. Hydrogen Energy 2013, 38, 9961-9972.

(41) Susmozas, A.; Iribarren, D.; Zapp, P.; Lin $\beta$ en, J.; Dufour, J. LifeCycle Performance of Hydrogen Production via Indirect Biomass Gasification with $\mathrm{CO}_{2}$ Capture. Int. J. Hydrogen Energy 2016, 41, 19484-19491.

(42) Koj, J. C.; Wulf, C.; Schreiber, A.; Zapp, P. Site-Dependent Environmental Impacts of Industrial Hydrogen Production by Alkaline Water Electrolysis. Energies 2017, 10, 860.

(43) Bareiß, K.; de la Rua, C.; Möckl, M.; Hamacher, T. Life Cycle Assessment of Hydrogen from Proton Exchange Membrane Water Electrolysis in Future Energy Systems. Appl. Energy 2019, 237, 862872.

(44) Gabrielli, P.; Gazzani, M.; Mazzotti, M. The Role of Carbon Capture and Utilization, Carbon Capture and Storage, and Biomass to Enable a Net-Zero- $\mathrm{CO}_{2}$ Emissions Chemical Industry. Ind. Eng. Chem. Res. 2020, 59, 7033-7045.

(45) IEA. World Energy Outlook 2019; OECD Publishing: Paris, 2019.

(46) Ioannou, I.; D’Angelo, S. C.; Martín, A. J.; Pérez-Ramírez, J.; Guillén-Gosálbez, G. Hybridization of Fossil- and $\mathrm{CO}_{2}$-Based Routes for Ethylene Production Using Renewable Energy. ChemSusChem 2020, 13, 6370-6380.

(47) Häussinger, P.; Leitgeb, P.; Schmücker, B. Nitrogen. In Ullmann's Encyclopedia of Industrial Chemistry; Wiley-VCH Verlag $\mathrm{GmbH} \&$ Co. KGaA: Weinheim, Germany, 2000.

(48) ISO. In ISO 14040:2006 Environmental Management--Life Cycle Assessment--Principles and Framework; International Standards Organization, 2006.

(49) ISO. In ISO 14044:2006 Environmental Management--Life Cycle Assessment--Requirements and Guidelines; International Standards Organization, 2006.

(50) United States Geological Survey (USGS). Mineral Commodity Summaries 2020; U.S. Government Publishing Office: Washington, DC, 2020.

(51) Wernet, G.; Bauer, C.; Steubing, B.; Reinhard, J.; Moreno-Ruiz, E.; Weidema, B. The Ecoinvent Database Version 3 (Part I): Overview and Methodology. Int. J. Life Cycle Assess. 2016, 21, 12181230.

(52) Goedkoop, M.; Oele, M.; Leijting, J.; Ponsioen, T.; Meijer, E. Introduction to LCA with SimaPro; PRé Sustainability: Amersfoort, 2016.

(53) Ryberg, M. W.; Owsianiak, M.; Richardson, K.; Hauschild, M. Z. Development of a Life-Cycle Impact Assessment Methodology Linked to the Planetary Boundaries Framework. Ecol. Indicat. 2018, $88,250-262$.

(54) Ryberg, M. W.; Owsianiak, M.; Clavreul, J.; Mueller, C.; Sim, S.; King, H.; Hauschild, M. Z. How to Bring Absolute Sustainability into Decision-Making: An Industry Case Study Using a Planetary Boundary-Based Methodology. Sci. Total Environ. 2018, 634, 14061416.

(55) Hanafiah, M. M.; Hendriks, A. J.; Huijbregts, M. A. J. Comparing the Ecological Footprint with the Biodiversity Footprint of Products. J. Clean. Prod. 2012, 37, 107-114.

(56) Galán-Martín, Á.; Tulus, V.; Díaz, I.; Pozo, C.; Pérez-Ramírez, J.; Guillén-Gosálbez, G. Sustainability Footprints of a Renewable Carbon Transition for the Petrochemical Sector within Planetary Boundaries. One Earth 2021, 4, 565-583.

(57) Ryberg, M. W.; Andersen, M. M.; Owsianiak, M.; Hauschild, M. Z. Downscaling the Planetary Boundaries in Absolute Environmental Sustainability Assessments-A Review. J. Clean. Prod. 2020, 276, 123287.
(58) The World Bank. Gross value added at basic prices (GVA) (current US\$) https://data.worldbank.org/indicator/NY.GDP.FCST. CD (accessed Oct 20, 2020).

(59) Oxford Economics. The Global Chemical Industry: Catalyzing Growth and Addressing Our World's Sustainability Challenges; ICCA: Washington, DC, 2019.

(60) Huijbregts, M. A. J.; Steinmann, Z. J. N.; Elshout, P. M. F.; Stam, G.; Verones, F.; Vieira, M.; Zijp, M.; Hollander, A.; van Zelm, R. ReCiPe2016: A Harmonised Life Cycle Impact Assessment Method at Midpoint and Endpoint Level. Int. J. Life Cycle Assess. 2017, 22, 138-147.

(61) Towler, G.; Sinnott, R. Chemical Engineering Design. Principles, Practice and Economics of Plant and Process Design, 2nd ed.; Butterworth-Heinemann: Oxford, 2013.

(62) Schmidt, O.; Gambhir, A.; Staffell, I.; Hawkes, A.; Nelson, J.; Few, S. Future Cost and Performance of Water Electrolysis: An Expert Elicitation Study. Int. J. Hydrogen Energy 2017, 42, 3047030492.

(63) Zhang, X.; Bauer, C.; Mutel, C. L.; Volkart, K. Life Cycle Assessment of Power-to-Gas: Approaches, System Variations and Their Environmental Implications. Appl. Energy 2017, 190, 326-338.

(64) Sterner, T.; Barbier, E. B.; Bateman, I.; van den Bijgaart, I.; Crépin, A.-S.; Edenhofer, O.; Fischer, C.; Habla, W.; Hassler, J.; Johansson-Stenman, O.; Lange, A.; Polasky, S.; Rockström, J.; Smith, H. G.; Steffen, W.; Wagner, G.; Wilen, J. E.; Alpízar, F.; Azar, C.; Carless, D.; Chávez, C.; Coria, J.; Engström, G.; Jagers, S. C.; Köhlin, G.; Löfgren, Å.; Pleijel, H.; Robinson, A. Policy Design for the Anthropocene. Nat. Sustain. 2019, 2, 14.

(65) Willett, W.; Rockström, J.; Loken, B.; Springmann, M.; Lang, T.; Vermeulen, S.; Garnett, T.; Tilman, D.; DeClerck, F.; Wood, A.; Jonell, M.; Clark, M.; Gordon, L. J.; Fanzo, J.; Hawkes, C.; Zurayk, R.; Rivera, J. A.; De Vries, W.; Majele Sibanda, L.; Afshin, A.; Chaudhary, A.; Herrero, M.; Agustina, R.; Branca, F.; Lartey, A.; Fan, S.; Crona, B.; Fox, E.; Bignet, V.; Troell, M.; Lindahl, T.; Singh, S.; Cornell, S. E.; Srinath Reddy, K.; Narain, S.; Nishtar, S.; Murray, C. J. L. Food in the Anthropocene: The EAT-Lancet Commission on Healthy Diets from Sustainable Food Systems. Lancet 2019, 393, 447-492.

(66) Zhang, X.; Davidson, E. A.; Mauzerall, D. L.; Searchinger, T. D.; Dumas, P.; Shen, Y. Managing Nitrogen for Sustainable Development. Nature 2015, 528, 51-59.

(67) Cobo, S.; Dominguez-Ramos, A.; Irabien, A. Trade-Offs between Nutrient Circularity and Environmental Impacts in the Management of Organic Waste. Environ. Sci. Technol. 2018, 52, 10923-10933. 